\title{
Application of Early Sustainability Assessment to Support the Design of Industrial Systems
}

\author{
Margherita Peruzzini*, Marcello Pellicciari \\ University of Modena and Reggio Emilia, Modena (MO), Italy
}

(Received: September 02, 2017 / Revised: January 08, 2018; January 24, 2018 / Accepted: January 24, 2018)

\begin{abstract}
Nowadays industrial products require numerous aspects to be integrated and optimized contemporarily and interactively: mechanics, electronics, system control, management of material and information flows, interfaces, humanproduct interaction, as well as impacts on environment, costs and human factors. As a consequence, the design of industrial products has to combine new advanced functionalities and high performances by limiting production cost as well as environmental and social impacts. It means that the entire industrial system has to be designed looking towards sustainability. While attention to cost and environmental performance is not new, the analysis of social-related aspects is basically unexplored for industrial products. Achieving social sustainability includes forecasting human behaviours, actions and reactions, analysing how human beings interact with objects, tools, devices and interfaces, and assessing their physical and mental workload. The present research proposes an analytical approach to support the design of industrial products by providing an early sustainability assessment of the three aspects of sustainability (environment, cost and people). It adopts a feature-based approach and a set of key performance indicators (KPIs) to assess the sustainability of the manufacturing and assembly processes and to support an easy and preventive analysis during product design. The paper presents the application of such method to industrial cases.
\end{abstract}

Keywords: Design for Sustainability, Sustainable Manufacturing, Feature-based Analysis, Sustainability Assessment, Key Performance Indicators

*Corresponding Author, E-mail: margherita.peruzzini@unimore.it

\section{INTRODUCTION}

Modern companies increasingly need to innovate their products and processes to keep up with the competitive pressure, increase productivity, expand their market share, and create profitable products and systems. However, such economical development could bring to environmental issues (i.e., climate change, pollution or biodiversity loss) as well as social problems (i.e., health problems, unsafe working conditions, excessive physical and cognitive workload). A broad range of different approaches is described in literature, under the heading of sustainability assessment (SA). SA is defined as a complex appraisal method for supporting decision-making and policy in a broad environmental, economic and social context, improving the purely technical and scientific evaluation (Sala et al., 2015). In this context, companies are called to optimize the use of any kind of resources and consider the mutual impacts of their choices on three dimensions: profit, planet, and people (Fisk, 2010). However, SA practices need a robust and comprehensive framework and application methodologies to be effectively applied to real industrial issues. In particular, SA practices should be anticipated to the design stages to be really successful and bring real advantages to industry. In this context, design for sustainability (D4S) promotes the diffusion of sustainable design practices, considering all impacts due to both product and process on the three 
areas of sustainability from the design stage. However, D4S methods usually focus on one single aspect at a time: life cycle assessment (LCA) methods focus on environmental-related issues, eco-design and design for environment (DfE) methods directly addresses environmental issues, while ergonomics assessments and focus on humancentred (HCD) approaches investigate human-product interaction (UNEP, 2006). Actually sustainability assessment is mainly based on ex-post analyses to monitor the existing conditions on the basis of life cycle analysis (Heilala et al., 2008; Amrina and Vilsi, 2015; Gupta et al., 2015). Nevertheless academic activity on sustainability has been intense since the early 2010 and numerous examples demonstrated how the adoption of sustainability principles could gain competitive advantages for companies (Peruzzini et al., 2014), practical methods and tools for early sustainability assessment during design stages are still limited. As a consequence, actions are usually taken when products and/or processes are already developed. Diversely, the introduction of sustainability assessment during the design stages could optimize design solutions in short time, limit the engineering changes and avoid too long optimization loops (Conteras et al., 2009).

The purpose of this study is to define an analytic approach for early sustainability assessment considering environmental, economic and human aspects at the same time. The proposed assessment is based on:

1) an analytic approach, where the entire process is divided into stages and sub-stages,

2) a feature-based approach to predict the future production process from the 3D product model, and

3) a set of key performance indicators (KPIs) to measure the different typologies of impacts.

The analysis starts from the recognition of 3D CAD features and the formalization of the company knowledge about machines, processes and procedures to achieve robust assumptions and realistic estimations. For each stage, impacts on cost, environment and human beings are estimated. About social aspects, physical and cognitive workloads of the involved workers are assessed. Indeed, workload is fundamental in social assessment and strongly affects the human performance influencing time and cost (Hwang et al., 2008).

\section{RELATED WORKS}

\subsection{Sustainable Assessment of Industrial Products}

Recently approved regulations as well as evidences from real world are pushing companies towards the socalled sustainable manufacturing (SM), which is based on the balance among environmental, economic, and social objectives, the so-called "triple bottom line" (Slaper and Hall, 2011). Nevertheless numerous examples in literature demonstrated how adopting sustainability principles could gain competitive advantages for companies, especially if the assessments are carried out during the design stages, and contemporarily include all the areas of sustainability (Peruzzini et al., 2014). Only predicting the impacts before the product generation allows sustainable solutions to be identified in short time, avoiding numerous engineering changes and optimization loops (Conteras et al., 2009). One of the most common approaches to $\mathrm{SA}$ is life cycle design (LCD), which considers the entire lifecycle 'from cradle to grave' and the related impacts at each phase, from resources extraction through premanufacturing, manufacturing, transportation, use, recycling, and ultimately, disposal. Usually LCD includes the definition of key indicators to assess performances (e.g., functionality, manufacturability, serviceability, environmental impact) (Melk and Anderl, 2007). Different methods have been developed for these purposes: life cycle assessment (LCA), that considers the environmental impact during all phases of product lifecycle (ISO 14040, 2006; ISO 14044, 2006); life cycle cost analysis (LCCA), that associates total cost to all lifecycle activities (Nakamura and Kondo, 2006); or social life cycle assessment (sLCA) addressing the social dimension (Weidema, 2006). More recently various researches have coupled LCA, LCCA and SLCA analyses to support sustainable product design in different industrial sectors (Parent et al., 2010; Dobon et al., 2011; Peruzzini and Germani, 2014). Some of them have also focused on the analysis of the relations between cost and human-related aspects affecting sustainability (Falck and Rosenqvist, 2014).

In this context, several studies demonstrated the importance of adopting a holistic approach including the three areas of sustainability, considering the impact on the environment, the producing cost and the human beings, in order to increase the perceived product quality, to achieve a higher customers' satisfaction, as strategic keys to face the global competitiveness (Nappi and Rozenfeld, 2015). However, a review of the most recent researches about SA in industry, especially in manufacturing industry, highlighted the lack of robust frameworks for early assessment to be applied from the initial design stages. Considering the publications on international journals during the last ten years (from 2006 up to now) on Scopus databases, we found that the majority of research works refer environmental-related aspects, and a good number refer to cost assessment. Only few works deals with social and human-related aspects. Four main methods for sustainability assessment have been also compared: environmental impact assessment (EIA), human development index (HDI), environmental footprint (EF), and life cycle assessment (LCA). A framework for the integration of dif- 
ferent SA methodologies has been recently proposed (Sala et al., 2015): it considers multi-criteria analysis (MCA), cost-benefit analysis (CBA), strategic environmental assessment (SEA), LCA, LCC, sLCA, the European social impact assessment (EuSIA) and the life cycle sustainability assessment (LCSA). However, it lacks of indicators and models to assess every single aspect into a coherent way.

\subsection{Sustainable Indicators for Industry}

Numerous indicators have been defined about sustainability assessment in industry in the last ten years. Firstly, the global report initiative (GRI) reported a set of guidelines that covers the sustainable development of the three sustainability pillars (i.e., profit, planet and people). Indicators are based on ISO 14010 (1996), ISO 14011 (1996), ISO 14012 (1996) standards for assessing the environmental impact, ISO 26000 (2010) standards for assessing social impacts, and OHSAS 18001 (2007) and OHSAS 18002 (2008) for health and safety risk management. Different methods has been developed after them: the environmental sustainability indicator (ESI) by Yale Center for Environmental Law \& Policy, the environment performance index (EPfI) by Yale University, the core environmental indicators (CEI) by the Organization for Economic Cooperation and Development (OECD), until the a set of indicators of sustainable development established by the United Nations Commission (UN-CSD) and the core set of indicators developed by the European Environmental Agency (EEA-CSI). Also some industries faced the issue to privately find out a proper set of indicators, like Ford that defined the Ford product sustainability index (Ford PSI). A comprehensive overview has been recently provided by (Joung et al., 2013).

Table 1 synthetizes the results of a survey about the most relevant research works published in the last ten years about sustainability assessment in industrial contexts, specifically referring to industrial product assessment. The majority of studies propose a late assessment on existing plants and projects, and only few of them contemporarily consider all the three areas of sustainability. Morbidoni et al. (2011) proposed an early assessment during design stages, but analysis is limited to costs. About social aspects, Falck and Rosenqvist (2014) estimated the impact of poor human sustainability, considering injured worker's rehab, replacement of the operator with a new employee and know-how dispersion in case of replacements, on company costs. However, none of them include ergonomic assessment of both physical and cognitive workload into the social perspective. In fact, ergonomics analysis seems to be usually disconnected from sustainability.

About human factors, analyses are generally carried out separately. The most common methods refer to physical workload assessment and the potential generation of musculoskeletal disorders (MSDs). Such analysis can be carried out by different methods, including NIOSH equation (Dempsey, 2002), Ovako Working posture Analysis System (OWAS) (Karhu et al., 1981), Occupational Repetitive Actions (OCRA) (Occhipinti, 1998). Rapid Upper Limb Analysis (RULA) (McAtamney and Corlett, 1993),

Table 1. Sustainability indicators adopted in industrial product design (from literature review)

\begin{tabular}{|c|c|c|c|}
\hline $\begin{array}{l}\text { Sustain. } \\
\text { Area }\end{array}$ & Indicators & Investigated items & References \\
\hline \multirow{4}{*}{ 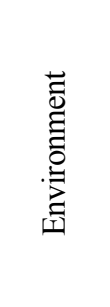 } & 1. Emission & Solid waste, air emission, energy waste & \multirow{4}{*}{$\begin{array}{l}\text { Heilala et al. (2008), Amrina and Vilsi (2015), } \\
\text { Gupta et al. (2015), Nappi and Rozenfeld } \\
\text { (2015), Hartini and Ciptomulyono (2015), } \\
\text { Yusof et al. (2013), Kulatunga et al. (2015), } \\
\text { Lofgren and Tillman (2011), Brondi and } \\
\text { Carpenzano (2011), Battini et al. (2014) }\end{array}$} \\
\hline & 2. Pollution & $\begin{array}{l}\text { Greenhouse gas emissions, hazard substance, } \\
\text { ozone depletion gases }\end{array}$ & \\
\hline & 3. Resource consumption & $\begin{array}{l}\text { Water used, material used, energy consump- } \\
\text { tion, land exploited }\end{array}$ & \\
\hline & 4. Habitat conservation & $\begin{array}{l}\text { Biodiversity, natural management and con- } \\
\text { servation }\end{array}$ & \\
\hline \multirow{3}{*}{ 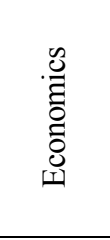 } & 5. Cost & $\begin{array}{l}\text { Manufacturing cost, material cost, logistics } \\
\text { cost, end of life cost }\end{array}$ & \multirow{3}{*}{$\begin{array}{l}\text { Amrina and Vilsi (2015), Gupta et al. (2015), } \\
\text { Falck and Rosenqvist (2014), Nappi and } \\
\text { Rozenfeld (2015), Morbidoni et al. (2011), } \\
\text { Hartini and Ciptomulyono (2015), Yusof et } \\
\text { al. (2013), Kulatunga et al. (2015), Loglisci } \\
\text { et al. (2014), Barletta } \text { et al. (2014) }\end{array}$} \\
\hline & 6. Profit & Profit earned by the organization & \\
\hline & 7. Investment & Eco friendly investment & \\
\hline \multirow{3}{*}{ 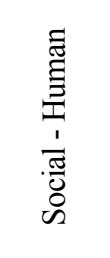 } & 8. Employee & $\begin{array}{l}\text { Health and safety, professional development, } \\
\text { employee satisfaction }\end{array}$ & \multirow{3}{*}{$\begin{array}{l}\text { Amrina and Vilsi (2015), Gupta et al. (2015), } \\
\text { Hartini and Ciptomulyono (2015), Yusof et } \\
\text { al. (2013), Falck and Rosenqvist (2014), } \\
\text { Barletta et al. (2014), Loglisci et al. (2014), } \\
\text { Yoon et al. (2016), Battini et al. (2014), } \\
\text { Stambolian et al. (2016) }\end{array}$} \\
\hline & 9. Customers & $\begin{array}{l}\text { Health and safety of the product at use phase, } \\
\text { customer satisfaction }\end{array}$ & \\
\hline & 10. Community & $\begin{array}{l}\text { Product responsibility (justice, fairness, equi- } \\
\text { ty, human rights, public service policy) }\end{array}$ & \\
\hline
\end{tabular}


Rapid Entire Body Assessment (REBA) (Hignett and McAtamney, 2000) or Workplace Ergonomic Risk Assessment (WERA) (Rahman et al., 2011). REBA, RULA, and NIOSH can be used for assessing the physical issues connected to static tasks, while OCRA and OWAS can be validly used for the repetitive tasks. In most cases, the discrete event simulation (DES) is used to segment the activities performed into sub-activities whose harmful level can be easily inferred. However, such methods generally require high level of detail and real process monitoring, which exclude their application to preliminary design stages and make it difficult and time-consuming for industry. In addition, the assessment of cognitive workload into the social perspective of sustainability is not included, even if it has been demonstrated that both mental demands and physical workload highly affect the human performance (Hwang et al., 2008). In particular, physical workload may be defined as tasks which require that the operators' muscles work, with the participation of the musculoskeletal, cardiorespiratory and nervous systems (Sluiter, 2006), while mental workload is a multidimensional concept depending on the worker characteristics (e.g., experiences, attention and skills) and task features, such as task load and procedures (Young and Stanton, 2004). Indeed, product design (i.e., assembly features) can directly influence numerous tasks at the shop floor, determining the workers' physical workload and mental workload, due to the involved cognitive resources (Perry et al., 2008). Such aspects should be taken into consideration in a comprehensive and complete sustainability assessment.

From the literature review, two main issues in early SA of industrial products have been identified:

- lack of practical guidelines to have a consolidated assessment of environmental, cost and humanrelated issues for industrial products, and to include human factors analysis in sustainability assessment;

- lack of structured methodologies to anticipate the assessment to the preliminary design stages in order to effectively support the product design. Impacts are usually evaluated on real plants and existing systems; as a consequence, SA is an evaluation tool instead of a design tool.

\section{RESEARCH APPROACH}

\subsection{The "Design for Sustainability" Approach}

The research proposes an analytic D4S approach suitable for industrial products, based on an early assessment of the three areas of sustainability. The approach is feature-based, which means that it retrieves the process information from the $3 \mathrm{D}$ product models to fasten the assessment and make it suitable for industry. Indeed, the analysis of 3D product geometry and their association to manufacturing and assembly processes, necessary to realize the designed items, allows to automatize the assessment and make it possible also during the design stages, to predict the impacts and to compare design solutions. The assessment is expressed by a set of KPIs related to three analyses, defined by authors as follows: Early Environmental Assessment (EEA), Early Cost Assessment $(E C A)$, and Early Human Assessment (EHA). For each of them, a set of models of impact is defined to measure KPIs.

The early assessment is based on the above-mentioned feature-based analysis. It considers the product features extracted from 3D CAD models and the exploitation of the company knowledge, properly formalized. Product geometric data are extracted from the 3D CAD model, while data about production sites, processes, machines, and information about company plants, working conditions, and positions assumed by workers can be gathered from the company knowledge. Knowledge formalization found on industrial best practices, specific company procedures and general procedures for a certain industrial sector. Data can be preventively defined and stored as a common knowledge base. It represents the preliminary data preparation phase, which is delicate but absolutely important for the successful adoption of the proposed approach. According to such knowledge, the most suitable production process can be inferred from the $3 \mathrm{D}$ product features, as the output of the process.

In order to synthetize, the proposed approach is based on three main steps:

1. Analysis of the product features: the 3D CAD product model is analysed to identify the most significant product features, characterizing its geometry, such as the type of surfaces (i.e., flat surfaces, curve surfaces, holes) and their functional role (i.e., functional holes for mating, aesthetic surfaces);

2. Recognition of the related processes: it is based on a quantitative estimating technique and, in particular, adopts the feature-based analytic approach (Wierda, 1991). It is a quantitative estimating technique that uses the product features to describe the geometric information at different levels of detail and to collect all functional and technological information (e.g., tolerances, surface finishing, manufacturing cycle). Such an approach allows to link geometric and non-geometric to technological and assembly features in order to predict the following manufacturing process. Recognition is based on the decomposition into basic features and the correlation between geometric features and process features. The association allows the product to be be analysed and related 
to its process according to a set of pre-defined list of sub-processes. Such an association is possible due to a proper data formalization of the process knowledge and the merge between geometric data and logical information (i.e., design requirements, system configuration, technical specification, plant features, company best practices);

3. Early assessment of sustainability impacts: process models defined in the previous step are populated with data referring to machines' tasks, operators' actions, etc. taken from the company knowledge formalization. Assessment is based of a set of "models of impacts" that relate the process parameters (as estimated) and the selected KPIs. Such models are related to a set of scenarios, which represent how the value chain (made up of the company, suppliers and customers) will behave. For each sustainability area, a set of KPIs is defined. A set of models of impacts is defined on the basis of process parameters, as described in the following section, which values usually vary from company to company, and from sector to sector. Considering the entire product lifecycle, different data and models of impact can be associated to the manufacturing, use and end-of-life phases.

Figure 1 shows the overall approach.

The proposed approach represents a significant contribution to "design for sustainability" due to its flexibility and its capacity to embrace all aspects of sustainability at a time. It is very powerful, since it can be adapted to very different products and is able to model a lot of different scenarios. However, it requires a deep data analysis and robust knowledge formalization. Knowledge formalization is structured by models of impacts in order to make method application easy and suitable for industrial contexts, and to reduce the implementation effort. The proposed steps can be carried out manually or, more effectively, automatically by a proper feature recognition toolkit. Valuable examples of successful feature-based software tools have been recently presented by Cicconi et al. (2010) and Germani et al. (2011).

\subsection{Knowledge Formalization}

The research proposes to couple environmental, economic and social-human assessments on the basis of the knowledge formalization. Knowledge formalization and structuring represent the core part of the proposed approach. It starts from the analysis of the most common technologies available in industry and is based on the categorization into classes and then categories, each of them characterized by a set of typical operations. Operations are expressed by proper equations using geometric and non-geometric parameters characterizing the specific operation (Figure 2, A). For instance, about chip removal manufacturing processes the geometric parameters (e.g., length, width, depth, roughness) can be connected to process machines, features and technological parameters considering the real process. Similarly it can be done for assembly tasks, where the process recognition links product features with the necessary assembly modalities (e.g., sequence of assembly, position of the operator, devices to be used, difficulties in handling). Such an analysis comprehends also human-related activities for a more integrated assessment (not only considering cost but also oth-

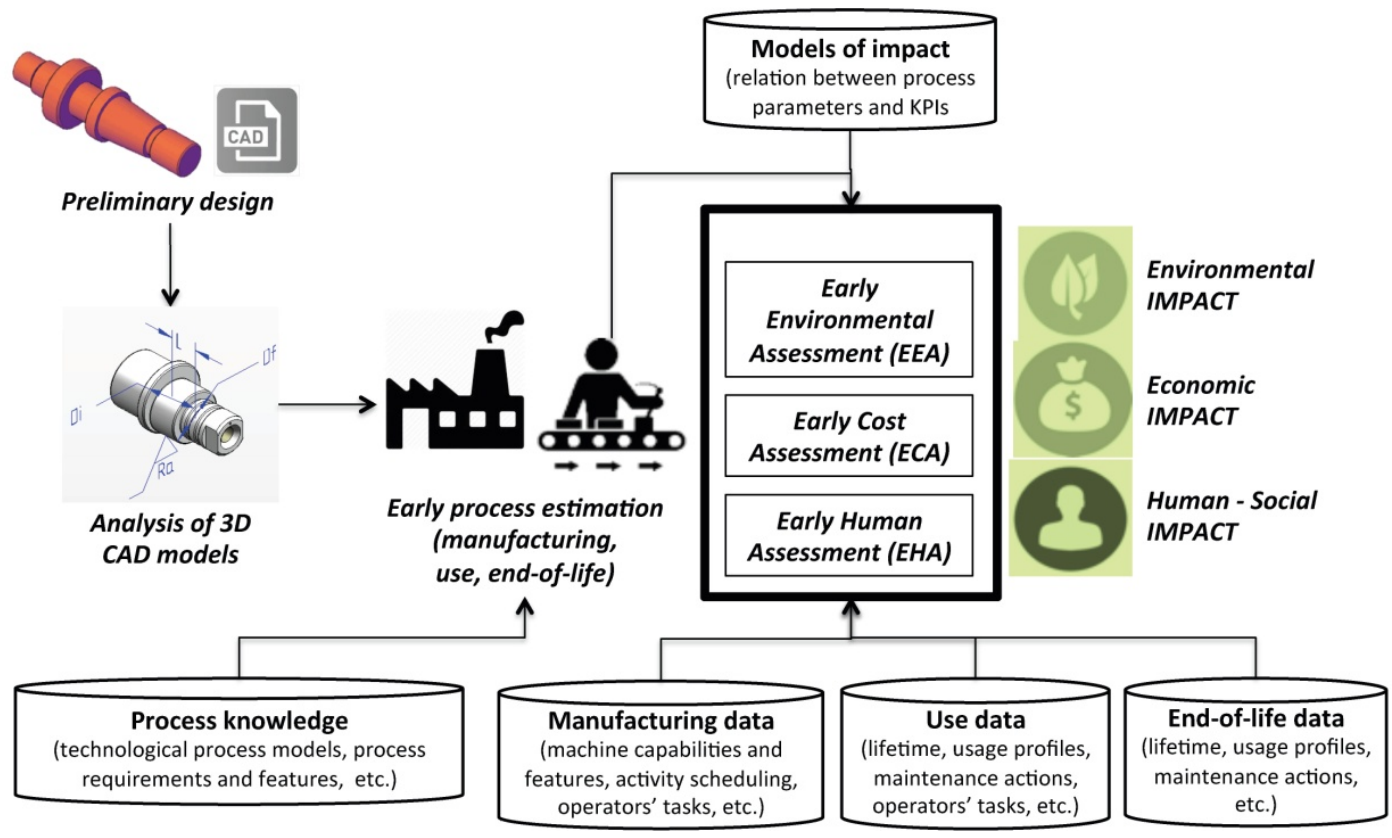

Figure 1. The overall approach for early sustainability assessment of industrial products. 
er sustainability factors) (Figure 2, B). For instance, manufacturing and assembly times are used not only for calculating the machining cost, but also the effective environmental impact exploiting LCA databases, and the operators efforts on the basis of the expected actions to manage the specific machine and handle the material during the specific process. About use and end-of-life, according to the product features and destination, a lifetime and an operative profile (working hourly, power required, number of operators, mean time to failure, efficiency curve, etc.) can be defined and the relative impacts estimated. Similar approaches have been recently adopted for cost estimation (Germani et al., 2011), but they are usually limited to the manufacturing cost estimation without including environmental and human impacts. In the present research such an approach is extended to all the areas of sustainability and detailed from human-social assessment, where robust models of impacts have not been defined yet.
Obviously, the resulting sustainability analysis is simplified since it omits some details that are not available during preliminary design stages. However, usually designers need rough estimations and comparative results instead of absolute results, and the proposed system is robust enough to validly compare alternatives and identify the more sustainable solutions among a set of alternative designs. The present research focuses on the formalization of knowledge referring to manufacturing, assembly and logistics processes, even if the approach could be extended also to other lifecycle phases.

\subsection{The Feature-Based Approach and Model of Impacts}

The main source of information during design stages is represented by the $3 \mathrm{D}$ product geometry and productrelated data managed as attributes by Product Lifecycle Management or Product Data Management (PLM-PDM)

A)

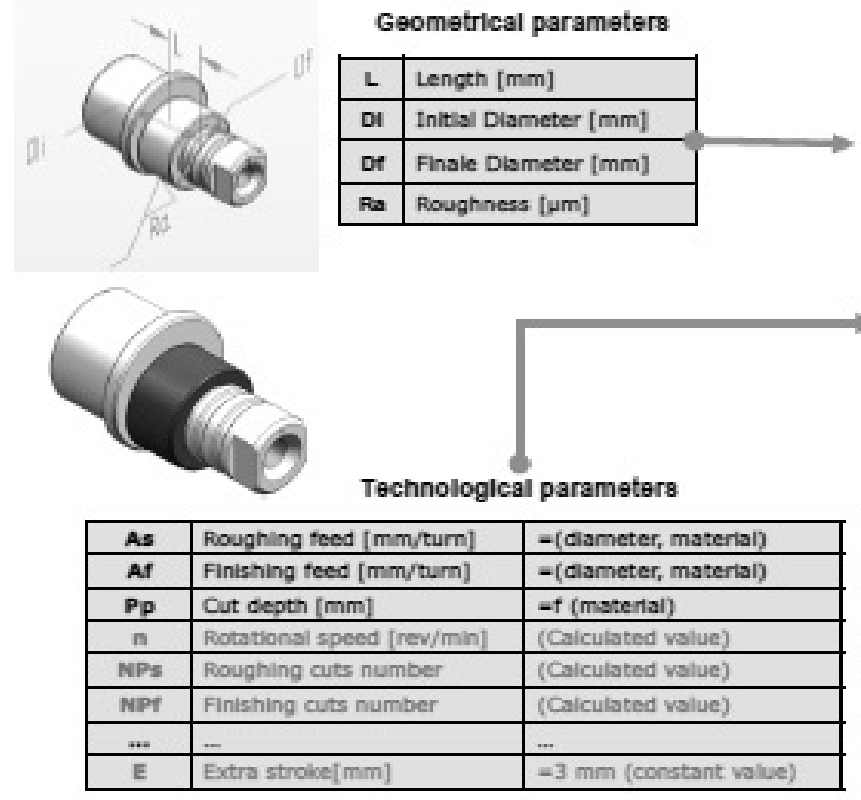

B)

\begin{tabular}{|ll|ll|ll|}
\hline \multicolumn{2}{|c}{ REBA } & \multicolumn{2}{c|}{ OCRA } \\
\hline NCK & neck flexion/extension & U & upper arm flexion/extension & NXVH & Operations with Very High demand of force \\
\hline NSD & neck side bending & URS & upper arm: shoulder raised & NXHG & Operations with High Intense demand of force \\
\hline NTW & neck twist & UAB & upper arm: abduction & NXMO & Operations with Moderate demand of force \\
\hline T & trunk flexion/extension & LA & lower arm flexion/extension & TX & Time consumed for the operation \\
\hline TSD & trunk side bending & LAA & lower arm: abduction & AZ & Number of actions per minute averaged on all the \\
\hline TTW & trunk twist & W & wrist flexion/extension & & tasks assigned to the operator. \\
\hline LG & leg flexion/extension & WSD & wrist side bending & REC & $\begin{array}{l}\text { Number of 8-10 min rest pauses could be given to } \\
\text { the operator in the entire 8 hour daily shift. }\end{array}$ \\
\hline LBNT & leg bending & WTW & wrist twist & CHKP & $\begin{array}{l}\text { It's the sum of the all 3 parameters that calculate } \\
\text { the repetitivity. }\end{array}$ \\
\hline F & carried static load & CUP & Couplings score & &
\end{tabular}

Figure 2. Examples of knowledge formalization: manufacturing process modelling by equations linking geometric and non-geometric parameters (A) and manual operation modelling for postural assessment (B). 
systems. Geometric information can be easily retrieved from 3D CAD and logic information is expressed as attributes in the PDM-PLM systems. They combined interpretation supports the recognition of the manufacturing and assembly features and other related processes.

The proposed approach is defined "feature-based" and "analytic." It is feature-based because it starts from the reading of the geometric and non-geometric features of the CAD product models, which are usually defined during the design phase using CAD software tools. It is analytic because it links the geometric features and the logical features of the product with the process features related to the technological and assembly processes. Therefore, estimation is based on the decomposition of the whole product, every item of the bill of material (BOM), its basic geometric features, and the correlation between such features and the manufacturing and assembly process features. Due to this association, the 3D models and the PLM-PDM attributes can be used to generate significant information in order to determine the related manufacturing and assembly processes. Such association is possible due to a proper formalization of the manufacturing knowledge and the relations between manufacturing items and cost-environmental-human impacts. Such an approach is defined "quantitative" since it is based on the measurement of specific data, real or inferred by the context. Such a quantitative approach has been suc- cessfully used for cost estimation (Rajkumar, 2003; Germani et al., 2011). Few interesting feature-based costing technology has been developed and deployed as knowledge-based systems (Cicconi et al., 2010; Shehab and Abdalla, 2006).

According to this procedure, manufacturing and assembly operations can be mapped with a specific set of geometric and non-geometric elements defined as a set of manufacturing and assembly features thanks to a set of "models of impact." It means that processes are matched with machines' tasks, operators' actions, etc. For each sustainability area, a set of KPIs is defined. Assessment is based on "sub-models" able to assess the specific impact by relating the process parameters to each indicator. In this way, product model and data can be represented are linked to the process features and be used to predict the real process in a simplified manner. Different models are defined: cost models, environmental models, and human impact models. Knowing formalization is fundamental to create reliable models to estimate the impacts of product features on cost, environment, and social aspects respectively.

As far as cost estimation by ECA, manufacturing costs can be successfully predicted as proposed by Germani et al. (2011). For each manufacturing class and category, a cost model can be defined to calculate the costs for machining, stock, ancillary operations, and set-up

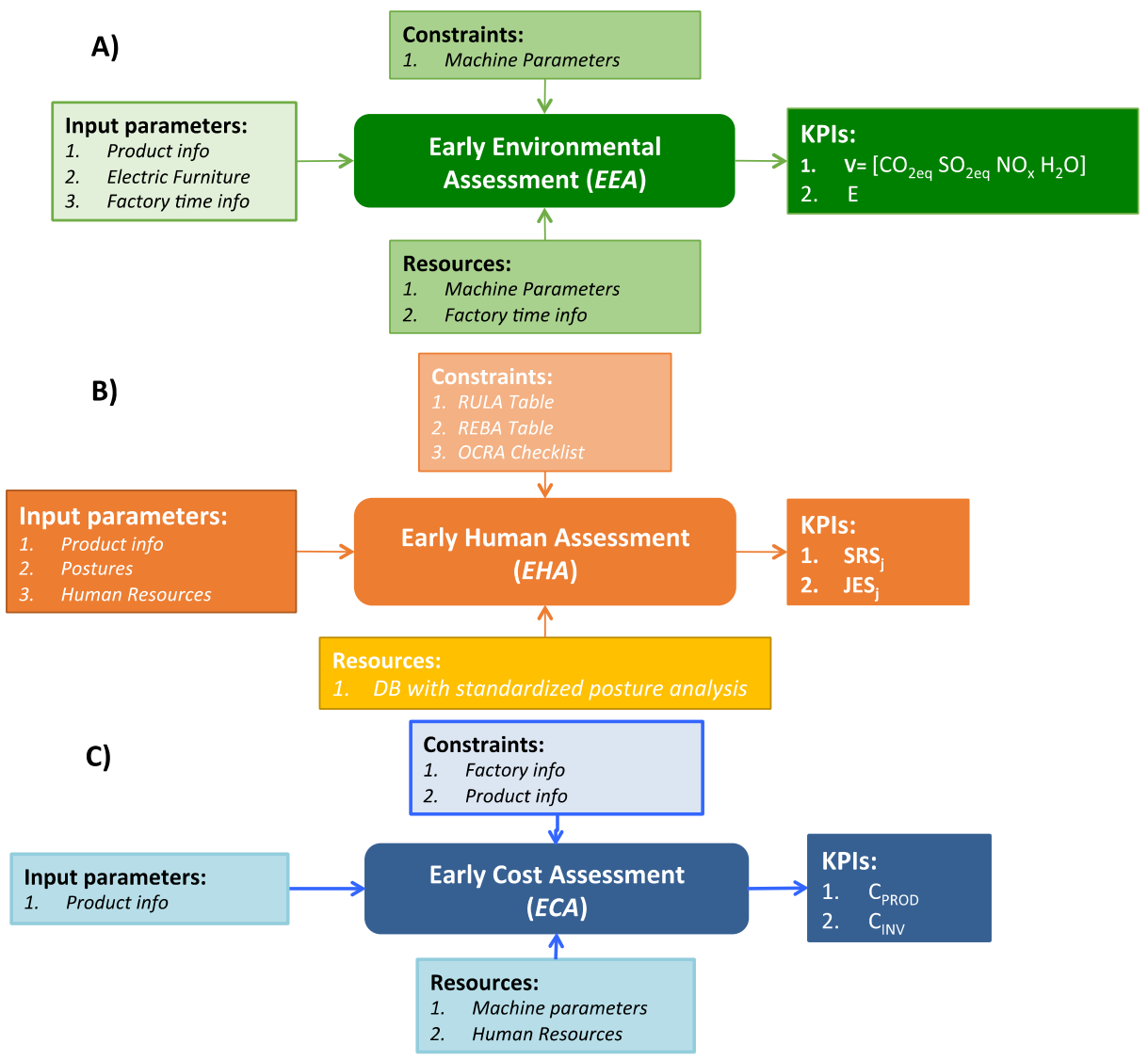

Figure 3. Model of impacts synthesis for EEA (A), EHA (B) and ECA (C). 
operations. Moreover, for each manufacturing operation either automated or manual, the involved geometric and technological parameters can be defined, and formulas expressing their relation can be defined. Similarly, assembly cost is defined considering different assembly typologies and estimating the necessary time using basic assembly rules (Boothroyd, 1992). Different types of assemblies are considered and valorised. For manual operations, cost is obtained considering the time required and the hourly cost of the people involved; for automatic operations, cost is obtained considering the time required and the hourly cost of the machine or the robot used.

As far as environmental impact estimation by EEA, numerous LCA tools exist (e.g., Gabi, SimaPro, and ECO.IT) but they required considerable amounts of detailed information, so they are usually used at the end of product development, when the process is already well defined. In the design stage, designers do not typically need absolute estimations but instead need comparative analysis to understand which design solution can better satisfy the project requirements and the sustainability targets. Therefore, a simplified analysis connected to 3D model features can be performed adopting a CADintegrated LCA approach, which connects LCA software databases with CAD model features, as proposed by Morbidoni et al. (2011).

About human impact assessment by EHA, a new assessment model has been defined. It is based on two measures: 1) Static Risk Score (SRS) that provides a static risk factor, and 2) Job Exposure Score (JES) that provides a dynamic risk factor considering the effect of task frequency and repetitiveness. The SRS is obtained by forecasting two techniques adopted to assess physical ergonomics: Rapid Upper Limb Assessment (RULA) and Rapid Entire Body Assessment (REBA). The JES is calculated on the basis of task frequency by means of OCRA checklist (Occhipinti and Colombini, 2016). Figure 3 shows a synthetic description of the model of impacts defined, be detailing the input and output parameters and the resources necessary for each analysis. Table 2 summarizes the KPIs and the parameters considered for each assessment area. Table 3 provides a more detailed overview of the human assessment metrics' scoring used in the proposed approach.

Table 2. KPIs for early sustainability assessment

\begin{tabular}{|c|c|c|c|c|}
\hline $\begin{array}{l}\text { Sust. } \\
\text { Area }\end{array}$ & KPIs & $\begin{array}{l}\text { Unit of } \\
\text { meas. }\end{array}$ & How to measure & Parameters \\
\hline \multirow{7}{*}{ EEA } & \multirow{2}{*}{$\begin{array}{l}\text { Energy } \\
\text { consumption }(E)\end{array}$} & \multirow{2}{*}{$\mathrm{kW}$} & \multirow{7}{*}{$\begin{aligned} \overline{E E A}_{T O T}= & \overline{E E A}_{M A N}+\overline{E E A}_{U S E} \\
& +\overline{E E A}_{E O L} \\
\overline{E E A}_{M A N}= & \bar{V}_{W S}+\bar{V}_{o p}+\bar{V}_{l} \\
\overline{E E A}_{U S E}= & \bar{V}_{P}+\bar{V}_{H} \\
\overline{E E A}_{E O L}= & \bar{V}_{D}+\bar{V}_{R} \\
\bar{V}= & {\left[C \mathrm{CO}_{2} e q ; \mathrm{SO}_{2} e q ; \mathrm{NO}_{x} e q ; \mathrm{H}_{2} \mathrm{O}\right] }\end{aligned}$} & $\bar{V}_{w s}=$ impact produced by workstations involved \\
\hline & & & & $\overline{\boldsymbol{V}}_{\boldsymbol{o p}}=$ impact produced by operators involved \\
\hline & \multirow{5}{*}{$\begin{array}{l}\text { Environmental } \\
\text { impact vector }(V)\end{array}$} & \multirow{5}{*}{$\mathrm{g}$ or 1} & & $\bar{V}_{l}=$ impact produced by logistic operations \\
\hline & & & & $\overline{\bar{V}_{\boldsymbol{P}}}=$ impact produced during the product use \\
\hline & & & & $\bar{V}_{\boldsymbol{H}}=$ impact on humans during the product use \\
\hline & & & & ${\overline{V_{D}}}_{\boldsymbol{D}}=$ impact caused by dismantling \\
\hline & & & & $\bar{V}_{\boldsymbol{R}}=$ impact caused by recycling \\
\hline \multirow{6}{*}{ EHA } & \multirow{3}{*}{$\begin{array}{l}\text { Static Risk Score } \\
(S R S)\end{array}$} & \multirow{3}{*}{ No. } & \multirow{6}{*}{$\begin{aligned} & \overline{E H A}_{T O T}= \overline{E H A}_{M A N}+ \\
&+\overline{E H A}_{E O L} \\
& \overline{E H A}_{M A N}= \bar{H}_{w S}+\bar{H}_{l} \\
& \overline{E H A}_{U S E}= \bar{H}_{P}+\bar{H}_{M} \\
& \overline{E H A}_{E O L}= \bar{H}_{D}+\bar{H}_{R} \\
& \bar{H}=[S R S ; J E S]\end{aligned}$} & $\overline{\boldsymbol{H}}_{\boldsymbol{w s}}=$ human impact on workstations \\
\hline & & & & $\overline{\boldsymbol{H}}_{\boldsymbol{l}}=$ human impact during logistic operations \\
\hline & & & & $\overline{\boldsymbol{H}}_{\boldsymbol{P}}=$ human impact during product use \\
\hline & \multirow{3}{*}{$\begin{array}{l}\text { Job Exposure Score } \\
(J E S)\end{array}$} & \multirow{3}{*}{ No. } & & $\overline{\boldsymbol{H}}_{\boldsymbol{M}}=$ human impact for product maintenance \\
\hline & & & & $\overline{\boldsymbol{H}}_{\boldsymbol{D}}=$ human impact for dismantling (if any) \\
\hline & & & & $\bar{H}_{R}=$ human impact for recycling (if any) \\
\hline \multirow{8}{*}{$E C A$} & \multirow{3}{*}{$\begin{array}{l}\text { Production cost } \\
\left(C_{P R O D}\right)\end{array}$} & \multirow{3}{*}{ euro } & \multirow{3}{*}{$\begin{aligned} \overline{E C A}_{T O T}= & \overline{E C A}_{M A N}+\overline{E C A}_{U S E} \\
& +\overline{E C A}_{E O L} \\
& -\end{aligned}$} & $\overline{\boldsymbol{C}}_{\boldsymbol{w s}}=$ cost for processes on workstations \\
\hline & & & & $\overline{\boldsymbol{C}}_{\boldsymbol{o p}}=$ cost for operators involved \\
\hline & & & & $\overline{\bar{C}_{l}}=$ cost for logistic operations \\
\hline & \multirow{5}{*}{$\begin{array}{l}\text { Investment cost } \\
\left(C_{I N}\right)\end{array}$} & \multirow{5}{*}{ euro } & $\overline{E C A}_{M A N}=\bar{C}_{w s}+\bar{C}_{o p}+\bar{C}_{l}$ & $\overline{\boldsymbol{C}}_{\boldsymbol{P}}=$ cost for the product (price for the user) \\
\hline & & & \multirow{4}{*}{$\begin{array}{l}\overline{E C A}_{U S E}=\bar{C}_{P}+\bar{C}_{H}+\bar{C} \\
\overline{E C A}_{E O L}=\bar{C}_{D}+\bar{C}_{R} \\
\bar{C}=\left[C_{P R O D} ; C_{I N}\right]\end{array}$} & $\overline{\boldsymbol{C}}_{\boldsymbol{H}}=$ cost for humans intervening during product lifetime \\
\hline & & & & $\bar{C}_{M}=$ cost for maintenance \\
\hline & & & & $\overline{\bar{C}}_{\boldsymbol{D}}=$ cost for dismantling \\
\hline & & & & $\overline{\bar{C}}_{R}=$ cost for recycling \\
\hline
\end{tabular}


Application of Early Sustainability Assessment to Support the Design of Industrial Systems

Vol 17, No 2, June 2018, pp.209-225, (c) 2018 KIIE

Table 3. Metrics' scores for EHA (Early Human Assessment)

\begin{tabular}{llll}
\hline REBA & RULA & OCRA & \multicolumn{1}{c}{ Level of MSD risk } \\
\hline 1 & 1 to 2 & 7,5 & Neglible risk, no action required. \\
\hline 2 to 3 & - & up to 11 & Low risk, change may be required. \\
\hline 4 to 7 & 3 to 4 & up to 14 & Medium risk, further investigation. \\
\hline 8 to 10 & 5 to 6 & up to 22,5 & High risk, investigate and implement changes. \\
\hline 11 & 7 & $22,6+$ & Very high, implement changes soon. \\
\hline
\end{tabular}

The feature-based approach allows linking the proposed KPIs with the product data in order to carry out a simplified assessment during the design stage. It aims at providing an early assessment by exploiting the information available and retrievable during the design stages, diversely from traditional approaches where such indicators are measured at the end of the process, providing a picture of the real scenario. Hereafter some examples of models of impact are provided. About manufacturing activities $\left(E E A_{M A N}\right)$, two different machine states can be defined: online time, when the workstation is currently in an active running mode, and offline time, when workstation is running but is not active on the piece production. For each state, a certain energy consumption rate is defined. The operative energy consumption $E_{a c t, k}$ can be assessed as indicated by Eq. (1):

$$
\begin{aligned}
\mathrm{E}(\text { act, } \mathrm{k})= & {[\mathrm{t}(\text { on }, \mathrm{k}) \times \mathrm{P}(\mathrm{ON}, \mathrm{k})} \\
& +\mathrm{t}(\mathrm{OFF}, \mathrm{k}) \times \mathrm{P}(\mathrm{OFF}, \mathrm{k})] /(60 \times \eta(\text { mech }))
\end{aligned}
$$

where $t_{o n, k}$ is the interval of time where operation is effectively performed of the $\mathrm{k}$ workstation, and depends on the specific operation and process, $\mathrm{P}_{\mathrm{ON}, \mathrm{k}}$ is the power consumption (in the ON state) of the specific $\mathrm{k}$ workstation, $\mathrm{t}_{\mathrm{OFF}, \mathrm{k}}$ is the time frame where the $\mathrm{k}$ workstation is not working, which depends on the specific operation and process, $\mathrm{P}_{\mathrm{OFF}, \mathrm{k}}$ is the power consumption (in the $\mathrm{OFF}$ state) of the specific $\mathrm{k}$ workstation, and $\eta_{\text {mech }}$ is the workstation mechanical efficiency. About $t_{\text {on, },}$, Eq. (2) indicates an example for milling process:

$$
\mathrm{t}=(\mathrm{p}+\mathrm{e}) / \mathrm{Va}+\mathrm{L} / \mathrm{Va} \times \mathrm{Np}
$$

where $\mathrm{p}$ is the depth of the operation, e is the extrastroke, $\mathrm{Va}$ is the machine speed, $\mathrm{L}$ is the length to be processed, and $\mathrm{N}_{\mathrm{P}}$ is the number of runs / cycles.

About EHA, the evaluation focuses on risk for the human beings involved in the different operations. The Total Score (TS) for each activity can be calculated as indicated by Eq. (3):

$$
\mathrm{TS}_{\mathrm{i}}=\mathrm{SRS}_{\mathrm{i}}+\mathrm{JES}_{\mathrm{i}}
$$

where $\mathrm{SRS}_{\mathrm{i}}$ is the static risk score for the $\mathrm{i}$ action and $J_{E S}$ is the Job Exposure Score for $\mathrm{i}$ action that considers the effect of repetitiveness (frequency of actions). A set of pre-defined postures for operators are defined considering the most common ones: standing, seating, crunching, kneeing, tiptoed, etc. For every type of posture, effect of distances is also considered. Firstly, $\mathrm{SRS}_{\mathrm{i}}$ is assessed by a manual or an automatic application of the RULA and REBA scores. Secondly, JES $_{\mathrm{i}}$ can be defined starting from $\mathrm{SRS}_{\mathrm{i}}$ and considering the duration and frequency of the activity by Eq. (4):

$$
\mathrm{JES}_{\mathrm{i}}=\mathrm{Dm}_{\mathrm{i}} \times \mathrm{SRS}_{\mathrm{i}} \times \mathrm{FW}_{\mathrm{i}}
$$

where $\mathrm{Dm}_{\mathrm{i}}$ is a Duration multiplier coefficient that considers the task frequency and the $\mathrm{FW}_{\mathrm{i}}$ is the fraction of time during which the operator works in respect with the total work time for the $\mathrm{i}$ action. The Duration Multiplied is determined according to Table $4 . \mathrm{FW}_{\mathrm{i}}$ is measured by Eq. (5).

$$
\mathrm{FW}_{\mathrm{i}}=\mathrm{tc}_{\mathrm{i}} / \mathrm{WS}_{\mathrm{i}} \times 100
$$

where $\mathrm{tc}_{\mathrm{i}}$ is the cycle time for the $\mathrm{i}$ action, and $\mathrm{WS}_{\mathrm{i}}$ is the total time on the specific workstation. FW $\mathrm{FW}_{\mathrm{i}}$ takes into account that breaks are usually required to have an active anti-fatigue effect.

The proposed approach is suitable for inclusion in a computer-integrated framework. Thanks to knowledge formalization, the proposed assessment models based on the feature-based approach can be merged with a CAD feature recognition systems and product structure information to carry out a semi-automatic analysis.

Table 4. The Duration Multiplier values adapted from OCRA Checklist

\begin{tabular}{cc}
\hline $\boldsymbol{F W}_{\boldsymbol{k}}$ frequency [\%] & $\boldsymbol{D m}_{\boldsymbol{k}}$ Duration multiplier \\
\hline $0 \div 12.5$ & $\underline{0.5}$ \\
\hline $12.5 \div 25$ & $\underline{0.65}$ \\
\hline $25 \div 37.5$ & $\underline{0.75}$ \\
\hline $37.5 \div 50$ & $\underline{0.85}$ \\
\hline $50 \div 62.5$ & $\underline{0.925}$ \\
\hline $62.5 \div 75$ & $\underline{0.95}$ \\
\hline $75 \div 87.5$ & $\underline{1}$ \\
\hline $87.5 \div 100$ & $\underline{1.5}$ \\
\hline
\end{tabular}




\section{THE INDUSTRIAL CASE STUDIES}

Such an approach has been implemented on real industrial case studies developed in collaboration with several Italian companies producing machines and packaging systems. A set of sub-assemblies, belonging to different type of machines and with different level of complexity, was chosen. They were redesigned with the aim of the proposed approach, measuring the sustainability level of existing solutions and defining the most proper design optimization strategy case by case. Preliminary tests on different industrial sectors (from packaging machines to woodworking systems, until pharmaceutics equipment) demonstrated interesting results. For each case, the necessary input data were collected by interviews to the com- panies' managers and workers, and by an accurate work of company knowledge formalization, carried out by experts. Table 5 shows the input data retrieved for each case study. Two particular cases are presented in details in the following sections.

In this study, method implementation refers only to the manufacturing and assembly stages, but it could be easily extended to the entire product lifecycle, considering manufacturing, use, and end-of life stages.

\subsection{Case Study no.1}

The case study no.1 is the first simple application where the proposed approach was applied. It refers to a component of a packaging machine (i.e., it is a machined

Table 5. Input data analysis for Early Sustainability Assessment for the case studies

\begin{tabular}{|c|c|c|c|}
\hline Area & Parameter & Unit of meas. & Description \\
\hline \multirow{3}{*}{ Product data } & 3D Model & $\begin{array}{l}\text { 3D natives formats } \\
\text { or STEP files }\end{array}$ & $\begin{array}{l}\text { Geometric and physical product properties. For assemblies, also BOM } \\
\text { structure. }\end{array}$ \\
\hline & Tech. info & $\begin{array}{l}\text { Specs/CAD-PLM } \\
\text { data }\end{array}$ & $\begin{array}{l}\text { Indications about the processes, not directly indicated into the 3D models } \\
\text { (treatments, logistics, etc.) }\end{array}$ \\
\hline & $\mathrm{Q}$ & [no.] & Batch quantity \\
\hline \multirow{3}{*}{ Factory data } & $t_{\mathrm{fc} \text { off }}$ & [h] & Interval time within facility is out of exercise (average) \\
\hline & $\underline{\mathrm{tacc}_{\mathrm{ac}}}$ & {$[\mathrm{min}]$} & Time for substituting machine equipment (average) \\
\hline & $\mathrm{t}_{\mathrm{set}}$ & {$[\mathrm{min}]$} & Necessary time for setup operations (average) \\
\hline \multirow{3}{*}{ Material } & Material & Type & $\begin{array}{l}\text { Raw material/Stock typology and related data (e.g., density, hardness, } \\
\text { manufacturability) }\end{array}$ \\
\hline & $\underline{\gamma_{\text {raw }}}$ & [euro/kg] & Raw material/Stock cost \\
\hline & $Q_{\text {raw }}$ & {$[\mathrm{kg}]$} & Quantity of row material \\
\hline \multirow{9}{*}{$\begin{array}{l}\text { Machine } \\
\text { parameters } \\
\text { (per each machine } \\
\text { involved) }\end{array}$} & $\eta_{\text {mecc }}$ & {$[\%]$} & Machine mechanical efficiency \\
\hline & $\underline{\mathrm{P}_{\mathrm{n}}}$ & {$[\mathrm{kW}]$} & Nominal electrical power consumption \\
\hline & $\underline{\mathrm{P}_{\mathrm{ON}}}$ & {$[\mathrm{kW}]$} & ON-state electrical power consumption \\
\hline & $\underline{\mathrm{P}_{\mathrm{OFF}}}$ & {$[\mathrm{kW}]$} & OFF-state electrical power consumption \\
\hline & $\mathrm{d}$ & {$[\mathrm{m}]$} & Distance between two workstations connected by a handling system \\
\hline & $\underline{\mathrm{C}_{\text {set }}}$ & [euro] & Setup cost \\
\hline & $\mathrm{C}_{\mathrm{acc}}$ & [euro] & Substitution equipment cost \\
\hline & $\underline{\mathrm{C}_{\mathrm{hr}}}$ & [euro/h] & Hourly labour cost \\
\hline & $\mathrm{W}$ & [no.] & Number of workers assigned to each workstation \\
\hline \multirow{5}{*}{ Logistics } & $\mathrm{G}$ & {$[\mathrm{km}]$} & Kilometres to cover \\
\hline & $\underline{\mathrm{n}_{\text {trk }}}$ & [no.] & Number of trucks involved (according to the maximum transportable weight) \\
\hline & $\zeta_{\text {emis }}$ & {$[\mathrm{g} / \mathrm{km}$ or $1 / \mathrm{km}]$} & $\begin{array}{l}\text { Quantity of emission per km (carbon emissions) - referred to the type of oil } \\
\text { consumed }\end{array}$ \\
\hline & Scons & {$[\mathrm{km} / \mathrm{l}]$} & $\begin{array}{l}\text { Kilometres covered per each fuel litre consumed. It has to be set according to } \\
\text { which type of truck is involved. }\end{array}$ \\
\hline & $\mathrm{c}_{1}$ & [euro] & $\begin{array}{l}\text { Specific cost per each km walked by. It has to be set according to which type } \\
\text { of truck is involved }\end{array}$ \\
\hline \multirow{3}{*}{ Human Resources } & $\mathrm{Az}$ & [actions/min] & $\begin{array}{l}\text { Number of actions per minute (averaged on all the tasks) assigned to the } \\
\text { operator. }\end{array}$ \\
\hline & $\mathrm{Tx}$ & {$[\mathrm{min}]$} & Time required for the operation. \\
\hline & Rec & [no.] & Number of rest pauses (approx. 8-10 min) on the 8-hour daily shift. \\
\hline \multirow{3}{*}{ Electric Supply } & $\underline{\mathrm{E}_{\text {renew }}}$ & {$[\mathrm{kWh}]$ or $\%$} & Electric mix renewable energy share \\
\hline & $\underline{E_{\text {fossil }}}$ & {$[\mathrm{kWh}]$ or $\%$} & Electric mix fossil energy share \\
\hline & $\mathrm{E}_{\text {other }}$ & {$[\mathrm{kWh}]$ or $\%$} & Electric mix percentage of other energy generation sources \\
\hline
\end{tabular}


plate). Figure 2 shows its 3D model and its main technological information. According to the design specification (i.e., S235JR steel material), the stock material can be selected from the company databases among the most proper stocks (i.e., Black Sheet 200/10 with dimensions of $260 \mathrm{~mm} \times 159 \mathrm{~mm} \times 20 \mathrm{~mm})$. After that, the manufacturing process can be inferred by the geometric analysis and manufacturing process recognition based on product features. The feature-based approach allows predicting the machining operations to be carried out for achieving the desired shapes. The estimated operations refer to: raw material processing (i.e., face milling and cut-out laser cutting), holes machining (i.e., by machining operations and later cutting depending on the holes' features), and finally cut-outs machining (i.e., an open pocket and a laser cutting). With this information, the three early assessments were carried out for the designed solutions. The synthesis of the assessment results about case study no. 1 is reported in Figure 3 (for EEA, EHA and ECA respectively). The use of the machines as shown in Figure 3 is justified by the low batch quantity (i.e., only 2). The three analyses refer to the manufacturing phase by neglecting the other phases, due to the complexity in predicting the part lifecycle without analysing the entire machine. Figure 4 shows an example, applied to the first manual operation (i.e., getting the stock from the rack), of the human assessment through the Static Risk Score (SRS) calculation. It considers the postures assumed during the operation execution, the weight to be loaded, and the time spent to execute the specific action.
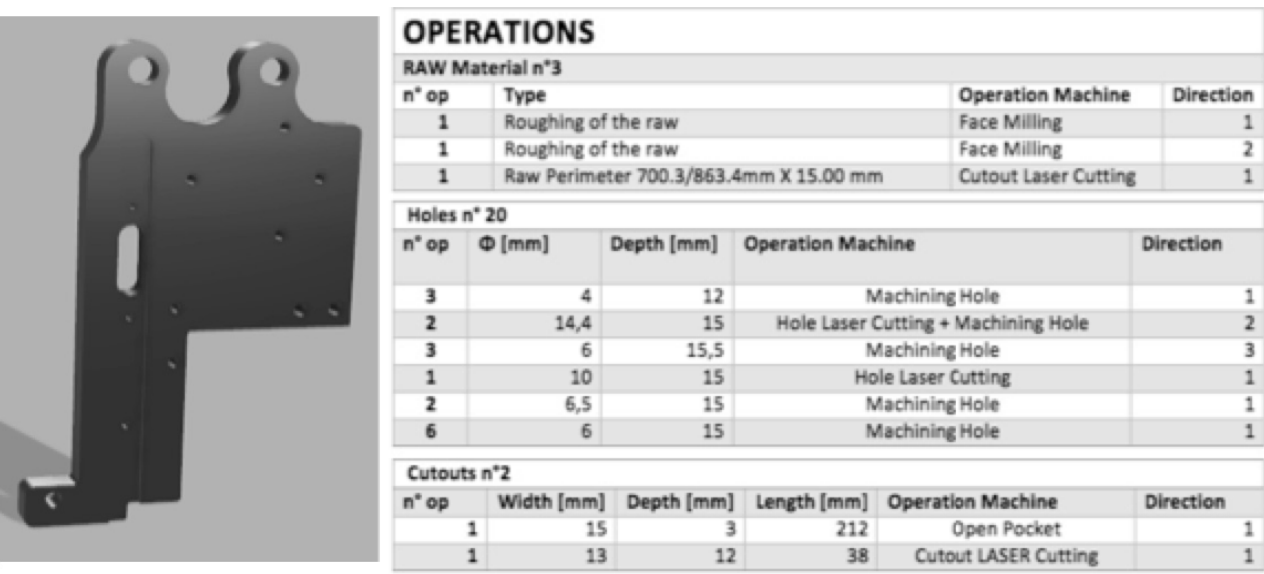

Figure 4. Case study no.1 of (machined plate from a packaging machine).
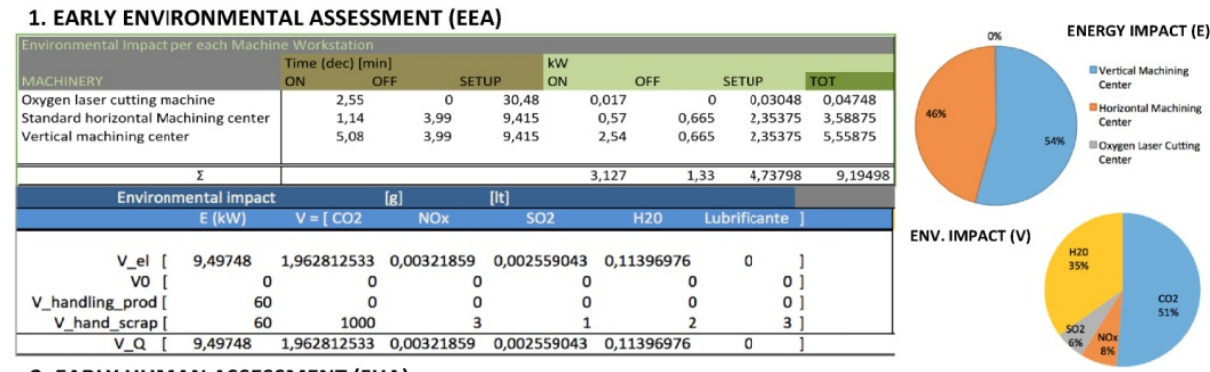

2. EARLY HUMAN ASSESSMENT (EHA)
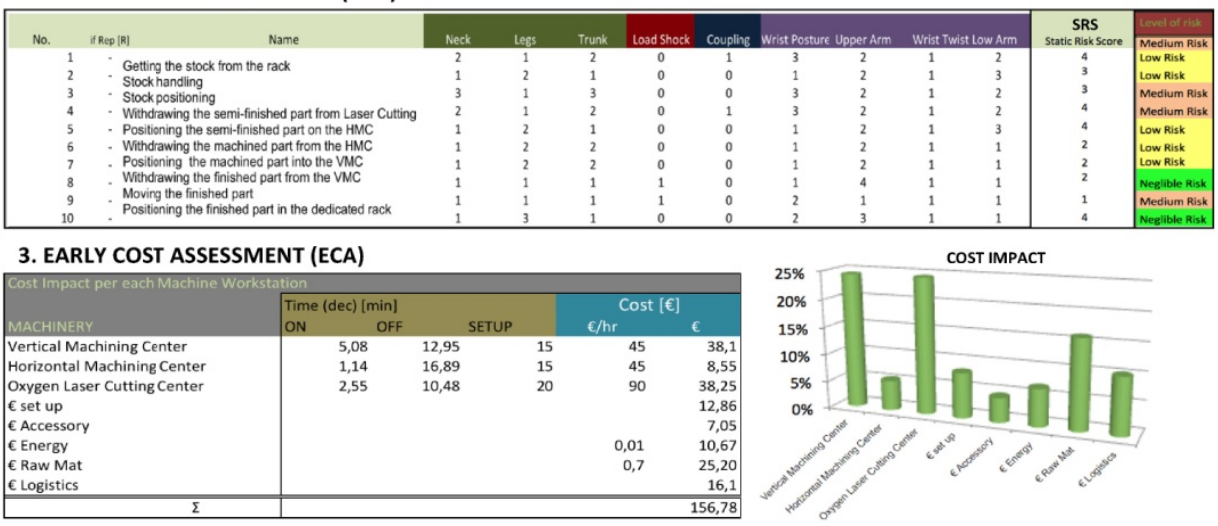

Figure 5. Results about EEA, EHA and ECA for the case study no.1. 
On the basis of the achieved results, the manufacturing process has been optimized in order to reduce impact on all the three areas. For instance:

- the vertical machining centre is the most used for the required operations, and it is responsible of the majority of the cost and environmental impact. The optimization of such machine can highly benefit the entire assessment;

- the laser cutting process is used for a short period of time, but it is very costly due to high set-up time and hourly cost. Manipulation of pieces from/to laser cutting machine is also quite risky of the operators. It suggests finding an alterative process to realize the cutting features. For instance, the easier alternative for the cutting process can be represented by mechanical cutting executed by the same vertical machine used for milling operations.

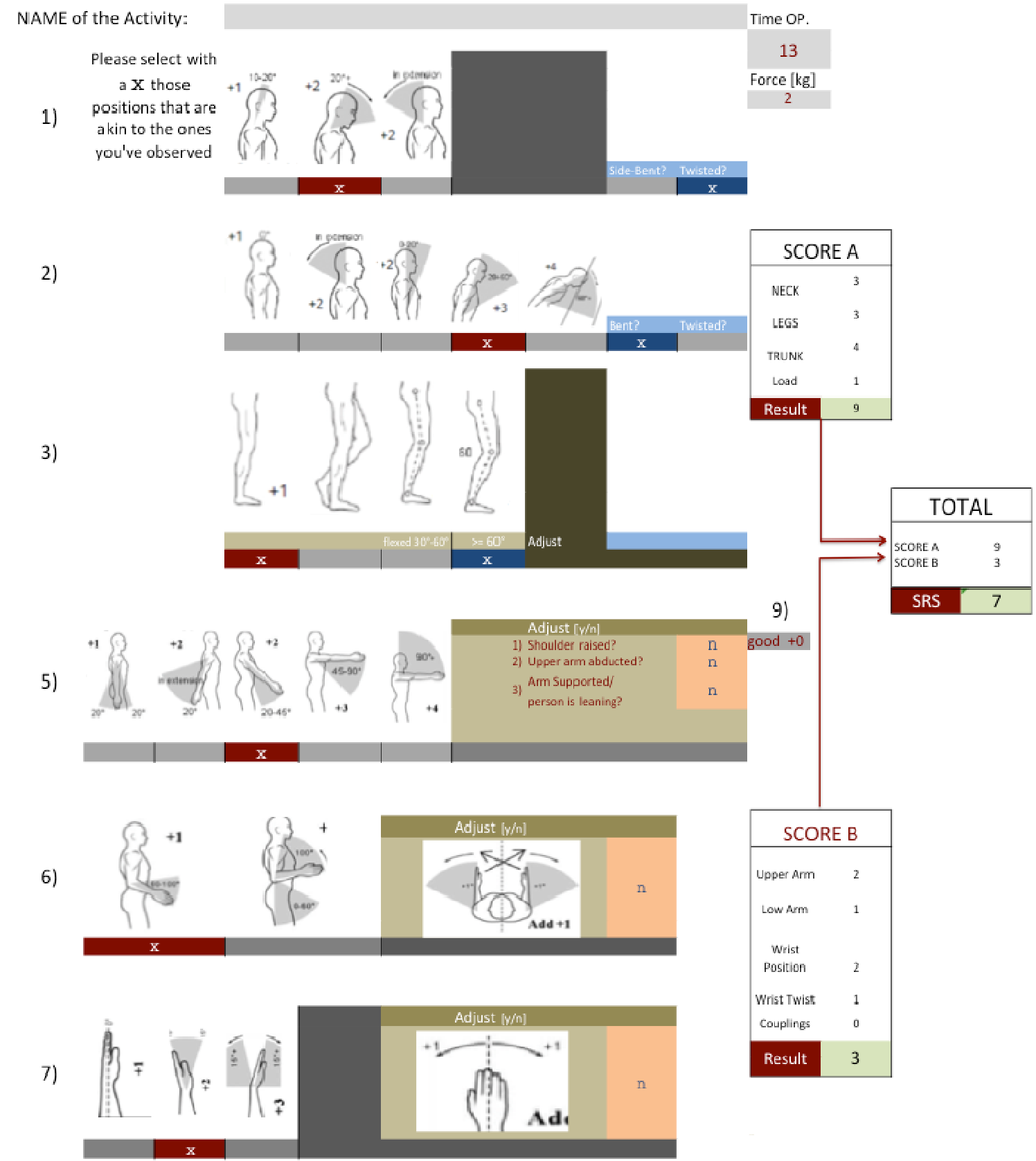

8)

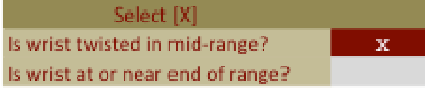

Figure 6. Example of EHA for operation no.1 (getting the stock from the rack). 


\subsection{Case Study no.2}

Case study no.2 refers to a more complex case, where an entire group of an automatic machine is analysed. The main components are examined similarly to the first case. Table 6 describes the bill of material and process related information. The last column, in particular, indicates the set of machines used to manufacture each part. About ECA, production costs and times were monitored directly on the machines from the real production. About EHA, workers carrying out similar tasks on similar products were observed and analysed by experts and a database with the reference postures were created. About EEA, a simplified analysis was carried out by SimaPRO LCA toolkit. The energy specific emissions were estimated considering from ENEL databases, which is the biggest energy supplier in Italy. As far as the emissions related to the raw materials, the study referred to $\mathrm{GaBi}$ free-accessible database. These are the results for all the emission factors related per each kg of AISI 304 Steel and Teflon. Last but not least, the postures assumed in the working operations are the postures presented in the database developed by the Italian National Institute for Injuries at Work (i.e., Istituto Nazionale Assicurazioni Infortuni sul Lavoro-INAIL). These postures were selected because according to INAIL (2011), these are the majority of cases of musculoskeletal disease related to work.

For each part and for the entire assembly, the EEA,
ECA and EHA were carried respectively. Also combination of the results from different analyses can be defined. For instance, Table 7 shows the correlation about ECA and EEA results for the case study no.2.

Such results allow pointing out a set of consideration to drive the following redesign actions, such as:

1. Logistic activities have a low impact with respect to the manufacturing activities;

2. Teflon pieces are the lowest pollutant pieces, the reason why is that if Teflon and steel are compared, results that Teflon is less pollutant than the steel and furthermore it requires less power, so less energy for cutting;

3. Some parts are the most pollutant components, mainly due to the high scrap rate to obtain the final shape.

Similarly, the EHA was carried out. Table 8 shows the main results for the list of actions analysed. It highlighted the hardest tasks and the main criticalities. Also in this case, some conclusions for redesign actions can be inferred:

1. Some operations should be redesigned in order to avoid uncomfortable posture because it holds the worst SRS condition (high risk);

2. Thanks to an inspection, the solution could be to raise the height of the initial rack, so that more comfortable postures are assumed by the workers;

Table 6. Bill of material analysis for case study no.2

\begin{tabular}{|c|c|c|c|c|}
\hline Product code & $\mathrm{Q}$ & Raw material & $\mathrm{No}^{\circ}$ op. & Equipped Machine \\
\hline \multirow{3}{*}{$\operatorname{xxxx}[1]$} & \multirow{3}{*}{1} & \multirow{3}{*}{ AISI 304 Steel Plank } & 1.1 & Bandsaw FORTE \\
\hline & & & 1.2 & Mazak Nexus 250-500 \\
\hline & & & 1.3 & GravoGraph LS 900 \\
\hline \multirow{3}{*}{$\operatorname{xxxx}[2]$} & \multirow{3}{*}{1} & \multirow{3}{*}{ Teflon } & 2.1 & Bandsaw FORTE \\
\hline & & & 2.2 & Mazak Nexus 250-500 \\
\hline & & & 2.3 & GravoGraph LS 900 \\
\hline \multirow{3}{*}{$\operatorname{xxxx}[3]$} & \multirow{3}{*}{2} & \multirow{3}{*}{ AISI 304 Steel Plank } & 3.1 & Bandsaw FORTE \\
\hline & & & 3.2 & Mazak Nexus 250-500 \\
\hline & & & 3.3 & GravoGraph LS 900 \\
\hline \multirow{3}{*}{$\operatorname{xxxx}[4]$} & \multirow{3}{*}{1} & \multirow{3}{*}{ Teflon } & 4.1 & Bandsaw FORTE \\
\hline & & & 4.2 & Mazak Nexus 250-500 \\
\hline & & & 4.3 & GravoGraph LS 900 \\
\hline \multirow{3}{*}{$\operatorname{xxxx}[5]$} & \multirow{3}{*}{1} & \multirow{3}{*}{ AISI 304 Steel Plank } & 5.1 & Mazak Nexus HCN 6800 \\
\hline & & & 5.2 & Bandsaw FORTE \\
\hline & & & 5.3 & Tumbler di Maio BVC 16 \\
\hline \multirow{3}{*}{$\operatorname{xxxx}[6]$} & \multirow{3}{*}{1} & \multirow{3}{*}{ AISI 304 Steel Plank } & 6.1 & Mazak Nexus HCN 6800 \\
\hline & & & 6.2 & Bandsaw FORTE \\
\hline & & & 6.3 & Tumbler di Maio BVC 16 \\
\hline \multirow{3}{*}{$\operatorname{xxxx}[7]$} & \multirow{3}{*}{1} & \multirow{3}{*}{ AISI 304 Steel Plank } & 7.1 & Mazak Nexus VTC $560 / 25$ \\
\hline & & & 7.2 & Bandsaw FORTE \\
\hline & & & 7.3 & Tumbler di Maio BVC 16 \\
\hline
\end{tabular}


3. The average risk level is low risk, so it can be considered as a well-structured task.
On the basis of such consideration, the group has been redesigned and the main results are shown in Table 9.

Table 7. Combination of EEA and ECA results for case study no.2

\begin{tabular}{lrrrrr}
\hline Name (or COD) & $\mathrm{CO}_{2} \mathrm{eq}[\mathrm{g}]$ & $\mathrm{NO}_{\mathrm{x}} \mathrm{eq}[\mathrm{g}]$ & $\mathrm{SO}_{2} \mathrm{eq}[\mathrm{g}]$ & $\mathrm{H}_{2} \mathrm{O}[\mathrm{l}]$ & Cost (euro) \\
\hline xxxx [1] & $79,287.3$ & 184.9 & 307.3 & 4.1 & 113.36 \\
\hline xxxx [2] & $28,179.5$ & 65.5 & 113.6 & 1.6 & 111.16 \\
\hline xxxx [3] & $168,747.6$ & 393.3 & 660.7 & 8.8 & 239.74 \\
\hline xxxx [4] & $7,638.9$ & 17.8 & 30.8 & 0.4 & 27.87 \\
\hline xxxx [5] & $277,043.8$ & 644.8 & $1,105.6$ & 15.1 & 84.77 \\
\hline xxxx [6] & $303,879.2$ & 707.2 & $1,213.8$ & 16.6 & 81.01 \\
\hline xxxx [7] & $212,252.5$ & 497.9 & 755.1 & 8.8 & 158.63 \\
\hline Logistic & 484.0 & 10.4 & 0.0 & 0.0 & 73.47 \\
\hline Raw Material & & & & & 295.74 \\
\hline Energy & & & & & 508.97 \\
\hline Total & $1,077,513$ & 2,522 & & & \\
\hline
\end{tabular}

Table 8. EHA results for case study no.2

\begin{tabular}{cccccccccccc}
\hline & \multicolumn{1}{c}{ Static Assessment } & \multicolumn{9}{c}{ Repetitiveness Assessment } & \multicolumn{2}{c}{ Final Score } \\
\hline$N o^{\circ}$ & if Rep $[R]$ & SRS & Time & $F W$ & $F R C$ & $F R W$ & $R E C$ & $D m$ & $J E S$ & TS Level of risk \\
\hline 1 & $\mathrm{R}$ & 8 & 2 & 1.0 & 1 & 1 & 1 & 0 & 0 & 8 & $\bigcirc$ \\
\hline 2 & $\mathrm{R}$ & 2 & 12 & 6.1 & 1 & 1 & 1 & 0 & 0 & 2 \\
\hline 3 & $\mathrm{R}$ & 5 & 12 & 6.1 & 0 & 1 & 1 & 0 & 0 & 5 \\
\hline 4 & $\mathrm{R}$ & 5 & 12 & 6.1 & 0 & 1 & 1 & 0 & 0 & 5 \\
\hline 5 & - & 3 & 12 & 0.0 & 0 & 0 & 1 & 0 & 0 & 3 \\
\hline 6 & $\mathrm{R}$ & 2 & 14 & 7.1 & 0 & 1 & 1 & 0 & 0 & 2 \\
\hline 7 & $\mathrm{R}$ & 2 & 14 & 7.1 & 0 & 1 & 1 & 0 & 0 & 2 \\
\hline 8 & - & 3 & 12 & 0.0 & 0 & 0 & 1 & 0 & 0 & 3 \\
\hline 9 & $\mathrm{R}$ & 6 & 20 & 10.1 & 0 & 1 & 1 & 0 & 0 & 6 \\
\hline 10 & $\mathrm{R}$ & 6 & 20 & 10.1 & 0 & 1 & 1 & 0 & 0 & 6 \\
\hline 11 & - & 3 & 12 & 0.0 & 0 & 0 & 1 & 0 & 0 & 3 \\
\hline 12 & $\mathrm{R}$ & 4 & 4 & 2.0 & 0 & 1 & 1 & 0 & 0 & 4 \\
\hline 13 & $\mathrm{R}$ & 4 & 4 & 2.0 & 0 & 1 & 1 & 0 & 0 & 4 \\
\hline 14 & - & 3 & 12 & 0.0 & 0 & 0 & 1 & 0 & 0 & 3 \\
\hline 15 & $\mathrm{R}$ & 3 & 12 & 6.1 & 0 & 0 & 1 & 0 & 0 & 3 \\
\hline 16 & $\mathrm{R}$ & 3 & 12 & 6.1 & 0 & 0 & 1 & 0 & 0 & 3 \\
\hline 17 & - & 3 & 12 & 0.0 & 0 & 1 & 1 & 0 & 0 & 3 \\
\hline
\end{tabular}

Table 9. Sustainability results after redesign (savings with respect to the original design)

\begin{tabular}{|c|c|c|}
\hline Sustainability results & Metrics (unit of measurements) & Saving \\
\hline \multirow{2}{*}{ Environmental impact (EHA) } & Energy consumption (E) & $-20 \%$ \\
\hline & Environmental impact vector (V) & $-14 \%$ \\
\hline \multirow{2}{*}{ Human impact (EHA) } & Static Risk Score (SRS) & $-30 \%$ \\
\hline & Job Exposure Score (JES) & $-22 \%$ \\
\hline \multirow{2}{*}{ Cost impact (ECA) } & Production cost $\left(\mathrm{C}_{\mathrm{PROD}}\right)$ & $-16 \%$ \\
\hline & Investment $\operatorname{cost}\left(\mathrm{C}_{\mathrm{IN}}\right)$ & $-10 \%$ \\
\hline
\end{tabular}




\subsection{Results Discussion}

The actions taken significantly benefit the overall product and process sustainability for the analysed components due to the creation of more efficient processes, fewer and faster operations to be executed, reduced numbers of parts to be moved, handled, and managed, and reduced energy consumption. As a result, a more sustainable manufacturing process is realized, which is characterized by reduced costs, a lower human impact, and a fewer environmental impact, as indicated in Table 9. In particular, product structure simplification and the optimization of some manufacturing processes contributed to achieve the higher results in terms of sustainability: a reduced number of parts means fewer process operations, fewer machines, fewer errors during part assembly, and fewer actions to be taken. Having a simplified evaluation of the sustainability and a consolidated overview of the design consequences on cost, environment and people, is very useful to make strategic decision-making, from the preliminary design stages, on both products and processes. It allows optimizing the design issues (i.e., assemblability, logistics, process organization, etc.), reducing costs, controlling the environmental impacts, and facilitating the human intervention during manufacturing and use phases (e.g., maintenance).

The contribution of this study is the definition of a method to carry out an early sustainability assessment for the companies to drive machine redesign. Designers and managers can be supported in decision-making to find a trade-off between the environmental, human and cost aspects, on the basis of the comparison of the results obtained from the global sustainability assessment. The method does not propose alternatives in a proactive way but highlight the critical areas and can be used to validly compare alternative product and process solutions. In particular, the proposed feature-based approach allows identifying the manufacturing process and supporting quick and timely redesign. With respect to the current state of the art, the proposed approach combines the three sustainability aspects to simultaneously optimize the product from the three different viewpoints (i.e., cost, environment and people). This study demonstrated the importance of merging the three aspects, which are usually investigated separately, and proved how the sustainability assessment can be directly connected to global product cost.

The proposed approach represents a new operative way to accomplish an early and complete sustainability analysis during design to achieve sustainable manufacturing. The main advantages are the holistic view, the inclusion of human factors in the product-process sustainability analysis, and the adoption of a feature-based approach to define the impact models. On the other hand, the main drawbacks of the proposed study are the knowledge formalization stage and data recovering as input data for the assessment, and the limitation to manufacturing phases.
Indeed, the company knowledge management needs to be extended and validated by more numerous case studies to be effectively adopted by a wide range of companies with different types of products.

Finally, method application is still manual and based on excel files and visual basic macros. Further research developments will be oriented to integrate such an approach in existing software toolkits for early estimation, that currently considers only cost impact. Such an approach will integrate the analysis with also environmental and human-related aspects to provide a wider and more correct early sustainability assessment.

\section{CONCLUSIONS}

The paper describes an integrated feature-based approach for early sustainability assessment to support industrial system design. It allows assessing environmental, economic and human impacts from the analysis the product features and defining the related processes on the basis of the company knowledge, in order to anticipate product-process critical issues and inefficiencies during the design stages, when changes are easier, more powerful, and less expensive. Preliminary testing on industrial cases demonstrated the validity of the proposed approach to support designers to have a clear overview of the potential impacts and to drive strategic decision-making. Future works will focus on developing models of impacts for specific product typology and industrial sector, to be integrated into a software solution.

\section{REFERENCES}

Amrina, E. and Vilsi, A. L. (2015), Key Performance Indicators for Sustainable Manufacturing Evaluation in Cement Industry, Procedia CIRP, 26, 19-23.

Barletta, I., Andersson, J., Johansson, B., May, G., and Taisch, M. (2014), Assessing a proposal for an energy-based overall equipment effectiveness indicator through discrete event simulation, Proceedings of the 2014 Winter Simulation Conference, IEEE Press Piscataway, NJ, USA, 1096-1107.

Battini, D., Persona, A., and Sgarbossa, F. (2014), Innovative real-time system to integrate ergonomic evaluations into warehouse design and management, Computers \& Industrial Engineering, 77, 1-10.

Boothroyd, G. (1992), Assembly Automation and Product Design, Marcel Dekker, New York.

Brondi, C. and Carpenzano, E. (2011), A modular framework for the LCA-based simulation of production systems, CIRP Journal of Manufacturing Science and Technology, 4(3), 305-312.

Cicconi, P., Germani, M., and Mandolini, M. (2010), 
How to support mechanical product cost estimation in the embodiment design phase, Proceedings of the 17th ISPE International Conference on Concurrent Engineering, Cracow, Poland, 465-477.

Conteras, A. M., Rosa, E., Pérez, M., Langenhove, H. V., and Dewulf, J. (2009), Comparative life cycle assessment of four alternatives for using by-products of cane sugar production, Journal of Cleaner Production, 17(8), 772-779.

Dempsey, P. G. (2002), Usability of the revised NIOSH lifting equation, Ergonomics, 45(12), 817-828.

Dobon, A., Cordero, P., Kreft, F., Østergaard, S. R., Antvorskov, H., Robertsson, M., Smolander, M., and Hortal, M. (2011), The sustainability of communicative packaging concepts in the food supply chain. A case study: part 2. Life cycle costing and sustainability assessment, The International Journal of Life Cycle Assessment, 16(6), 537-547.

Falck, A. C. and Rosenqvist, M. (2014), A model for calculations of the costs of poor assembly ergonomics (part 1), International Journal of Industrial Ergonomics, 44(1), 140-147.

Fisk, M. (2010), People, planet, profit: How to embrace sustainability for innovation and business growth, Kogan Page Limited, London.

Germani, M., Cicconi, P., Mandolini, M. (2011), Manufacturing cost estimation during early phases of machine design, Proceedings of the International Conference on Engineering Design ICED11, Technical University of Denmark, 198-209.

Gupta, S., Dangayach, G. S., and Singh, A. K. (2015), Key Determinants of Sustainable Product Design and Manufacturing, Procedia CIRP, 26, 99-102.

Hartini, S. and Ciptomulyono, U. (2015), The relationship between lean and sustainable manufacturing on performance: Literature review, Procedia Manufacturing, 4, 38-45.

Heilala, J., Vatanen, S., Tonteri, H., Montonen, J., Lind, S., Johansson, B., and Stahr, J. (2008), Simulationbased sustainable manufacturing system design, Proceedings of the 2008 Winter Simulation Conference, Miami, Florida, 1922-1930.

Hignett, S. and McAtamney, L. (2000), Rapid entire body assessment (REBA), Applied Ergonomics, 31(2), 201-205.

Hwang, S. L., Yau, Y. J., Lin, Y. T., Chen, J. H., Huang, T. H., Yenn, T. C., and Hsu, C. C. (2008), Predicting work performance in nuclear power plants, Safety Science, 46(7), 1115-1124.

INAIL, Istituto Nazionale per Assicurazione Infortuni sul Lavoro (2012), Un percorso formativo sulla prevenzione dei fattori di rischio tipici del settore metalmeccanico, Milano: Tipolitografina INAIL.

ISO 14010 (1996), Guidelines for environmental auditing - General principles, ISO.
ISO 14011 (1996), Guidelines for environmental auditing -Audit procedures-Auditing of environmental management systems, ISO.

ISO 14012 (1996), Guidelines for environmental auditing - Qualification criteria for environmental auditors, ISO.

ISO 14040 (2006), Environmental Management-Life Cycle Assessment - Principles and Framework, ISO.

ISO 14044 (2006), Environmental Management-Life Cycle Assessment-Requirements and Guidelines, ISO.

ISO 26000 (2010), Social responsibility, ISO.

Joung, C. B., Carrell, J., Sarkar, P., and Feng, S. C. (2013), Categorization of Indicators for sustainable manufacturing, Ecological Indicators, 24, 148-157.

Karhu, O., Harkonen, R., Sorvali, P., and Vepsalainen, P. (1981), Observing working posture in industry: Examples of OWAS application, Applied Ergonomics, 12(1), 13-17.

Kulatunga, A. K., Karunatilakeb, N., Weerasinghea, N., and Ihalawattaa, R. K. (2015), Sustainable manufacturing based decision support model for product design and development process, Procedia CIRP, 26, 87-92.

Lofgren, B. and Tillman, A. M. (2011), Relating manufacturing system configuration to life-cycle environmental performance: Discrete-event simulation supplemented with LCA, Journal of Cleaner Production, 19(17-18), 2015-2024.

Loglisci, C., Priarone, P. C., and Settineri, L. (2014), Development of sustainable manufacturing indicators focusing on human and work environment, Proceedings of the International Conference on Development, Energy, Environment, Economics (DEEE '14), Mathematics And Computers in Science and Engineering Series, 259-266.

McAtamney, L. and Corlett, E. N. (1993), RULA: A survey method for the investigation of work-related upper limb disorders, Applied Ergonomics, 24(2), 9199.

Melk, K. and Anderl, R. (2007), A generic framework for life cycle applications, Proceedings of the 3rd International Conference on Life Cycle Management, University of Zurich at Irchel.

Morbidoni, A., Favi, C., and Germani, M. (2011), CADintegrated LCA tool: Comparison with dedicated LCA software and guidelines for the improvement, Proceedings of the 18th CIRP International Conference on Life Cycle Engineering, 569-574.

Nakamura, S. and Kondo, Y. (2006), Hybrid LCC of appliances with different energy efficiency, The International Journal of Life Cycle Assessment, 11(5), 305-314.

Nappi, V. and Rozenfeld, H. (2015), The incorporation of sustainability indicators into a performance measurement system, Procedia CIRP, 26, 7-12. 
Occhipinti, E. (1998), OCRA: A concise index for the assessment of exposure to repetitive movements of the upper limbs, Ergonomics, 41(9), 1290-1311.

Occhipinti, E. and Colombini, D. (2016), A toolkit for the analysis of biomechanical overload and prevention of WSMDs: Criteria, procedures and tool selection in a step-by-step approach, International Journal of Industrial Ergonomics, 52, 18-28.

OHSAS 18001 (2007), Occupational health and safety management systems-Specification, OHSAS.

OHSAS 18002 (2008), Occupational health and safety management systems-Guidelines for the implementation of OHSAS 18001, OHSAS.

Parent, J., Cucuzzella, C., and Revéret, J. P. (2010), Impact assessment in SLCA: Sorting the sLCIA methods according to their outcomes, The International Journal of Life Cycle Assessment, 15(2), 164-171.

Perry, C. M., Sheik-Nainar, M. A., Segall, N., Ma, R., and Kaber, D. B. (2008), Effects of physical workload on cognitive task performance and situation awareness, Theoretical Issues in Ergonomics Science, 9(2), 95-113.

Peruzzini, M. and Germani, M. (2014), Design for sustainability of product-service systems, International Journal of Agile Systems and Management, 7(3/4), 206-219.

Peruzzini, M., Luzi, A., and Marilungo, E. (2014), Assessing sustainability and supporting compliance to standards in continuous industrial processes, International Journal of Product Lifecycle Management, $7(2 / 3)$.

Rahman, M. N. A., Rani, M. R. A., and Rohani, M. J. (2011), WERA: An observational tool develop to assess the physical risk factor associated with wrmds, Journal of Human Ergology, 40(2), 19-36.

Rajkumar, R. (2003), Decision engineering report series. Cost engineering: Why, what and how?, Cranfield University, UK.

Sala, S., Ciuffo, B., and Nijkamp, P. (2015), A systemic framework for sustainability assessment, Ecological Economics, 119, 314-325.

Shehab, A. and Abdalla, E. (2006), A cost-effective know- ledge-based reasoning system for design for automation, Journal of Engineering Manufacture, 220(5), 729-743.

Slaper, T. F. and Hall, T. J. (2011), The triple bottom line: What is it and how does it work?, Indiana Business Review, 86(1), 4-8.

Sluiter, J. K. (2006), High-demand jobs: age-related diversity in work ability?, Applied Ergonomics, 37(4), 429-440.

Stambolian, D., Eltoukhyb, M., and Asfoura, S. (2016), Development and validation of three dimensional dynamic biomechanical lifting model for lower back evaluation for careful box placement, International Journal of Industrial Ergonomics, 54, 10-18.

UNEP (United Nations Environment Programme) (2006), Eco design: Class of 2006: Industry Report Cards on Environment and Social Responsibility, UNEP/ Earthprint.

Weidema, B. (2006), The integration of economic and social aspects in life cycle impact assessment, International Journal of Life Cycle Assessment, 11(1), 89-96.

Wierda, L. S. (1991), Linking design, process planning and cost information by feature-based modelling, Journal of Engineering Design, 2(1), 3-19.

Yoon, S. Y., Ko, J., and Jung, M. C. (2016), A model for developing job rotation schedules that eliminate sequential high workloads and minimize betweenworker variability in cumulative daily workloads: Application to automotive assembly lines, Applied Ergonomics, 55, 8-15.

Young, M. S. and Stanton, N. A. (2004), Mental workload, in Stanton, N.A., Hedge, A., Brookhuis, K., and Salas, E. (Eds.), Handbook of Human Factors and Ergonomics Methods, Taylor and Francis Group, London.

Yusof, N. M., Saman, M. Z. M., and Kasava, N. K. (2013), A conceptual sustainable domain value stream mapping framework for manufacturing, Procedia CIRP 11th Global Conference on Sustainable Manufacturing, Berlin-Germany, 54-59. 